\title{
Future prospects in boron chemistry: new boron compounds and Lewis acids for catalysis and materials science
}

\author{
Guillaume Berionni* \\ Department of Chemistry, Namur Institute of Structured Matter, Université de Namur, Namur B-5000, Belgium. \\ *Correspondence to: Prof. Guillaume Berionni, Department of Chemistry, Namur Institute of Structured Matter, Université de \\ Namur, 61 Rue de Bruxelles, Namur B-5000, Belgium. E-mail: guillaume.berionni@unamur.be
}

How to cite this article: Berionni G. Future prospects in boron chemistry: new boron compounds and Lewis acids for catalysis and materials science. Chem Synth 2021;1:10. https://dx.doi.org/10.20517/cs.2021.11

Received: 18 Aug 2021 First Decision: 15 Sep 2021 Revised: 16 Sep 2021 Accepted: 18 Sep 2021 Fisrt online: 23 Sep 2021

Academic Editor: Bao-Lian Su Copy Editor: Yue-Yue Zhang Production Editor: Yue-Yue Zhang

\begin{abstract}
Boron-containing compounds have a wide range of structures and rich and multifaceted reactivity patterns. As a result, these compounds are being increasingly used in organometallic, supramolecular, organic and inorganic chemistry, as well as in catalysis and materials science. This perspective describes recent ground-breaking studies and their implications for the future development of new catalysts and materials containing one or several trivalent boron atoms.
\end{abstract}

Keywords: Boron chemistry, organoboron compounds, boron Lewis acids, boron materials, boronic acid derivatives, organoboranes

Due to their structural diversity and rich reactivity, boron-containing compounds are being increasingly used as building blocks in organic ${ }^{[1]}$, organometallic, supramolecular and inorganic synthesis, as well as in catalysis $^{[2]}$ and materials science ${ }^{[3]}$. While trivalent organoboron species are textbook examples of Lewis acids and trivalent boron substituents are electron-withdrawing groups by nature, the nucleophilic reactivity of the $\mathrm{C}-\mathrm{B}$ bond is readily increased by combining the trigonal boron atom with Lewis bases, anions or nucleophiles. Such activation of boronic acid derivatives is a widely used strategy in transition metalcatalysed (Suzuki-Miyaura cross-coupling reaction) and transition metal-free reactions $s^{[4-6]}$. As recent reviews and perspectives have highlighted the chemistry of tetracoordinate anionic boron intermediates used for the 


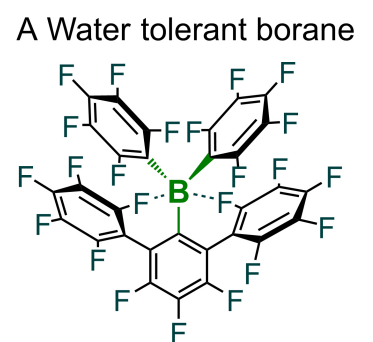

E Boron-nitrogen helicene

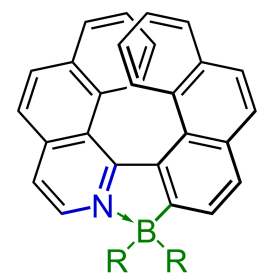

I BN-doped [10]-cyclo
paraphenylene

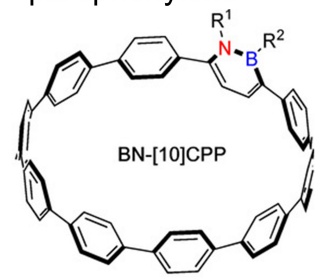

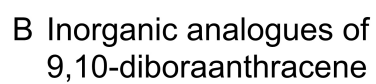

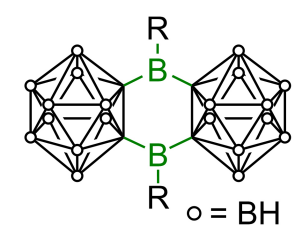

Antiaromatic polycyclic boron doped $\pi$-systems

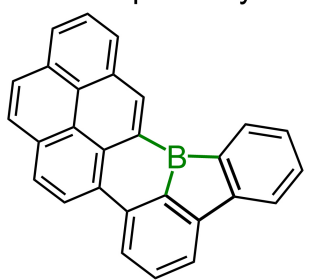

J Antiaromatic polycyclic boron doped $\pi$-systems



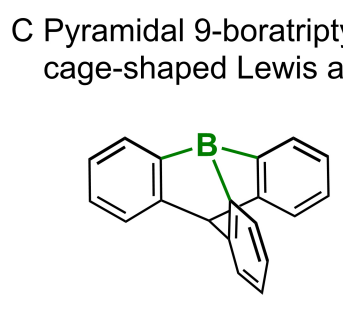

G Polyanionic redox active diborafluorene derivatives

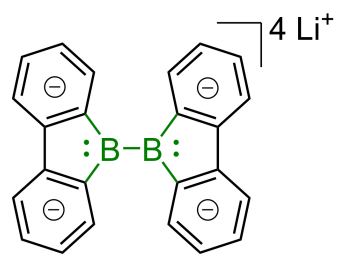

K Boron (III) subporphyrins

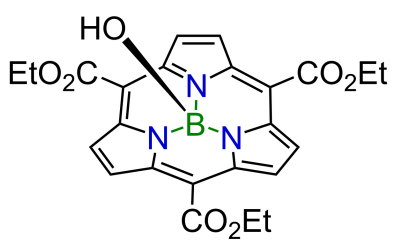

D Antiaromatic
perfluorinated borole<smiles></smiles>

$\mathrm{H}$ Cationic BN embedded aromatic hydrocarbons<smiles>FC(F)(F)N1c2ccccc2N2c3cccc4c3B(c3c2cccc31)N(c1ccccc1)c1cccc(c1)N4c1ccccc1</smiles>

Figure 1. New boron-, diboron- and boron heteroatom-doped aromatic compounds.

$\mathrm{C}-\mathrm{C}$ and $\mathrm{C}-\mathrm{B}$ bond formation ${ }^{[7-9]}$ of boryl anions, borylenes and diboron species ${ }^{[10,11]}$, and of the photochemical and photoinduced reactions with boron reagents ${ }^{[12-14]}$, they are not covered here. This perspective focuses on recent developments regarding new types of trivalent boron compounds and their applications for the design of boron-doped aromatic materials, of boron Lewis superacids and of new boron-based catalysts targeting the activation of small molecules and the $\mathrm{C}-\mathrm{H}$ borylation reactions.

Trivalent boron compounds are prototypical Lewis acids with a very wide range of Lewis acidities ${ }^{[15]}$. Triarylboranes are widely used as activators, catalysts and co-catalysts in a plethora of reactions ${ }^{[16-18]}$. The recent development of polyfluorinated triphenyldiphenyl boranes tolerant to air and water [Figure $1 \mathrm{~A}]^{[19]}$ will undoubtedly open new opportunities for improving well-established boron-mediated catalytic processes $^{[20]}$. Powerful boron Lewis acids and superacids with ever increasing Lewis acidity are also gaining increasing interest from the perspective of the recent intense development of new types of inorganic analogues, including diboraanthracene featuring carborane substituents [Figure 1B] $]^{[21]}$, pyramidal yet trivalent boron Lewis acids embedded in cage-shaped triptycene cores [Figure $1 \mathrm{C}]^{[22-24]}$ and antiaromatic perfluorinated boroles [Figure 1D] ${ }^{[25]}$. These unprecedented boron compounds with new structures and reactivities will enable the observation of new coordination modes at boron, in the isolation of long sought after reaction intermediates and new classes of boron-mediated reactions in the near future.

Helical boron-containing materials [Figure $1 \mathrm{E}]^{[26]}, \pi$-conjugated boron compounds embedded in polyaromatic antiaromatic architectures [Figure $1 \mathrm{~F}]^{[27]}$, redox-active tetraanionic diborafluorenes [Figure $1 \mathrm{G}]^{[28]}$, boron-nitrogen embedded polycyclic aromatic hydrocarbons [Figure $\left.1 \mathrm{H}\right]^{[29]}$, BN-doped cycloparaphenylenes [Figure $1 \mathrm{I}]^{[30]}$, highly emissive donor-acceptor arylamino-9-borafluorene [Figure $\left.1 \mathrm{~J}\right]^{[31]}$, 
A Conversion of $\mathrm{CO}_{2}$ to polycarbonates and cyclic carbonates

$\mathrm{B} \mathrm{B}\left(\mathrm{C}_{6} \mathrm{~F}_{5}\right)_{3}$ catalyzed $\mathrm{CO}_{2}$ hydrogenation

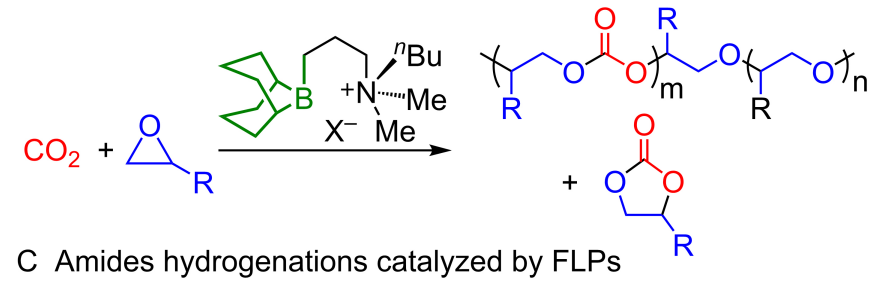

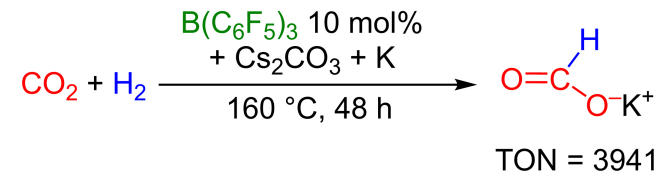

D Reductive cleavage of CO

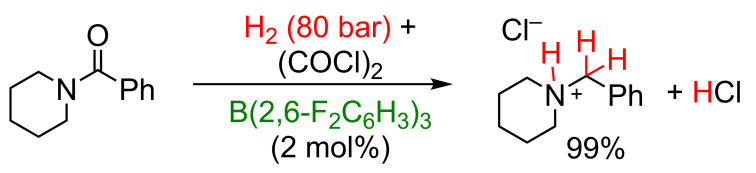



Figure 2. Boron mediated activation, hydrogenation or functionalization of small molecules.

A Directed electrophilic borylation of aldehydes with transient directing group<smiles>[R]c1cccc(C=O)c1C=O</smiles>

B Metallomimetic $\mathrm{C}-\mathrm{H}$ bonds activation with bifunctional catalysts

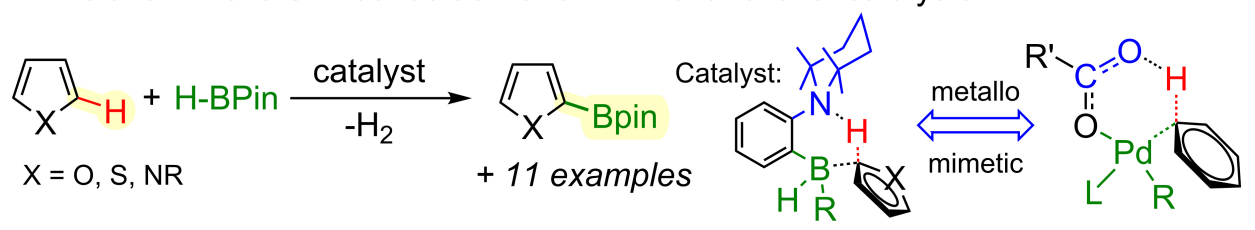

C Methane activation by a borenium ion and transformation in methylboronates

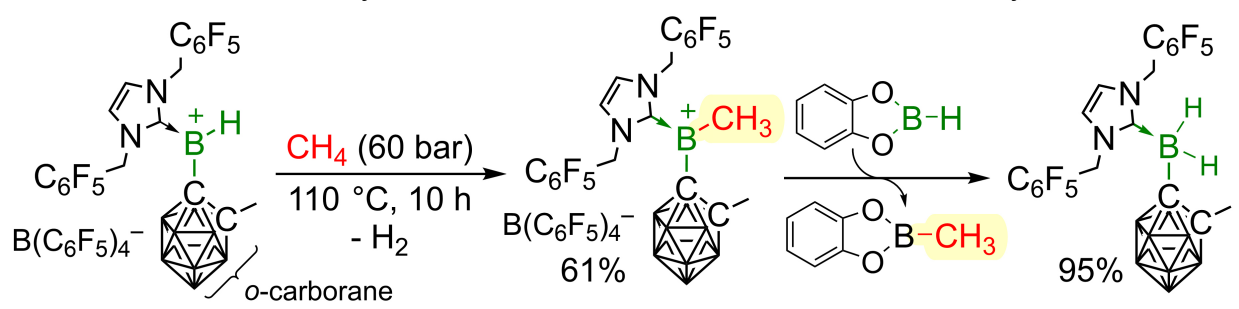

D Benzene $\mathrm{CH}$ activation and borylation by non-planar boron Lewis superacids

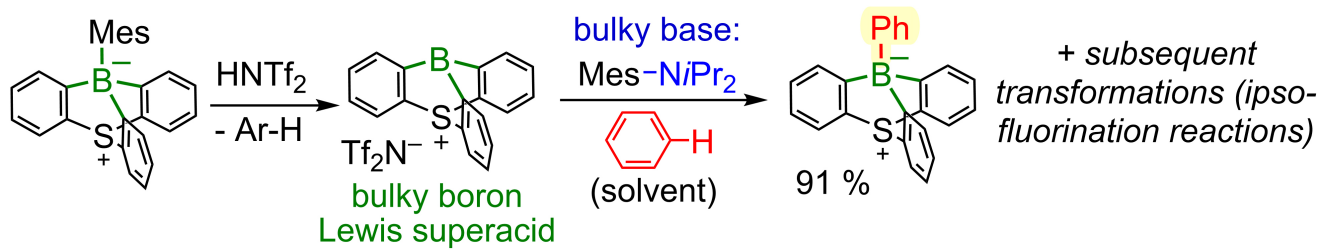

Figure 3. Recent seminal advances on $\mathrm{C}-\mathrm{H}$ activation and borylation reactions foreshadowing future catalytic applications.

bora subporphyrins [Figure $1 \mathrm{~K}]^{[32]}$ and thiophene-based polycyclic aromatic tricoordinate boron semiconductor [Figure $1 \mathrm{~L}]^{[33]}$ are all receiving increasing recognition for their outstanding optical, photophysical, electrochemical and photoresponsive properties. 
Trivalent organoboron compounds are of increasing importance for capturing and reacting with small molecules ${ }^{[3,35]}$. The boron-mediated conversion of carbon dioxide to cyclic carbonates ${ }^{[36]}$ and copolymers $[\text { Figure } 2 \mathrm{~A}]^{[37]}$ and to formate [Figure $\left.2 \mathrm{~B}\right]^{[3,33]}$ with bifunctional borylated catalysts is a rapidly evolving area of chemical catalysis oriented towards green chemistry. New highly efficient frustrated Lewis pairs have been successfully employed for the highly challenging catalytic hydrogenation of amides to amines [Figure $2 \mathrm{C}]^{[40,41]}$ and for the reductive cleavage of carbon monoxide [Figure $\left.2 \mathrm{D}\right]^{[42]}$.

The development of unprecedented transition metal-free borylation methodologies with transient protecting/directing groups [Figure $3 \mathrm{~A}]^{[43]}$ and the catalytic activation of $\mathrm{C}-\mathrm{H}$ bonds with bifunctional boron catalysts [Figure $3 \mathrm{~B}]^{[44]}$ has achieved momentous interest among synthetic chemists and are challenging transition-metals complexes traditionally used for the functionalization of heterocycles ${ }^{[45]}$. Frustrated Lewis pairs catalysts, often based on strong and bulky boron Lewis acids ${ }^{[46]}$, are increasingly used for transition metal-free $\mathrm{C}-\mathrm{H}$ bond activations and borylations processes ${ }^{[47,48]}$. The metallomimetic chemistry of boron compounds and the completely new area of metallomimetic catalysis are both rapidly evolving fields $s^{[49,50]}$.

Very recently, $\mathrm{N}$-heterocyclic carbene-stabilized o-carboranyl-substituted borenium ions were used for the very first transition metal-free $\mathrm{C}-\mathrm{H}$ bond activation and borylation of methane and longer alkanes [Figure $3 \mathrm{C}]^{[51]}$, and frustrated Lewis pairs constituted by weakly coordinating anion and pyramidal boron Lewis superacids were used for the $\mathrm{C}-\mathrm{H}$ bond activation and borylation of unactivated arenes and for their subsequent conversion to fluoroaromatics [Figure $3 \mathrm{D}]^{[52]}$. Thus, highly electron-deficient boron Lewis acids will likely be employed in the near future for the catalytic borylation, silylation and functionalization of hydrocarbons and for their subsequent functionalization.

Thus, the applications of boron reagents in $\mathrm{C}-\mathrm{H}$ functionalization and borylation are likely to also be increasingly used in chemistry in light of these seminal advances and are predicted to be ever growing due to the major interest in borylated building blocks in the academic community and chemical industry ${ }^{[53,54]}$. Thus, boron-based derivatives are important hybrid metal/non-metal compounds with high structural diversity and broad and rich applications in all fields of chemistry. Boron derivatives are anticipated to have a bright future and a profound impact on the future progress in chemical catalysis and materials science.

\section{DECLARATIONS}

\section{Acknowledgments}

Mr Ali Bensaida (University of Namur) is acknowledged for interesting discussions about this Perspective article.

\section{Authors' contributions}

The author contributed solely to the article.

\section{Availability of data and materials}

Not applicable.

\section{Financial support and sponsorship}

We acknowledge the University of Namur (www.unamur.be), the Namur Institute of Structured Matter (NISM) and the Fond National de la Recherche Scientifique (FRS-FNRS, grant number T.0012.21) for financial support. 


\section{Conflicts of interest}

The author declared that there are no conflicts of interest.

\section{Ethical approval and consent to participate}

Not applicable.

\section{Consent for publication}

Not applicable.

\section{Copyright}

(c) The Author(s) 2021.

\section{REFERENCES}

1. Budiman YP, Westcott SA, Radius U, Marder TB. Fluorinated aryl boronates as building blocks in organic synthesis. Adv Synth Cat 2021;363:2224-55. DOI

2. Carden JL, Dasgupta A, Melen RL. Halogenated triarylboranes: synthesis, properties and applications in catalysis. Chem Soc Rev 2020;49:1706-25. DOI PubMed

3. Shah S, Marandi P, Neelakandan PP. Advances in the supramolecular chemistry of tetracoordinate boron-containing organic molecules into organogels and mesogens. Front Chem 2021;9:708854. DOI

4. Wang H, Jing C, Noble A, Aggarwal VK. Stereospecific 1,2-migrations of boronate complexes induced by electrophiles. Angew Chem Int Ed Engl 2020;59:16859-72. DOI PubMed PMC

5. Hirano K, Uchiyama M. Inter-element boration reactions of carbon-carbon multiple bonds via lewis-basic activation of boron reagents. Adv Synth Cat 2021;363:2340-53. DOI

6. Sacramento M, Costa GP, Barcellos AM, Perin G, Lenardão EJ, Alves D. Transition-metal-free C-S, C-Se, and C-Te bond formation from organoboron compounds. Chem Rec 2021. DOI

7. Yang K, Song Q. Tetracoordinate boron intermediates enable unconventional transformations. Acc Chem Res 2021;54:2298-312. DOI PubMed

8. Taniguchi T. Advances in chemistry of N-heterocyclic carbene boryl radicals. Chem Soc Rev 2021;50:8995-9021. DOI PubMed

9. Maza RJ, Fernández E, Carbó JJ. Mapping the electronic structure and the reactivity trends for stabilized $\alpha$-boryl carbanions. Chemistry 2021;27:12352-61. DOI PubMed

10. Kong L, Cui C. Perspective on organoboron chemistry. Synlett 2021;32:1316-22. DOI

11. Kaur U, Saha K, Gayen S, Ghosh S. Contemporary developments in transition metal boryl complexes: an overview. Chem Coord Rev 2021;446:214106. DOI

12. Yadagiri B, Daipule K, Singh SP. Photoinduced borylation reactions: an overview. Asian J Org Chem 2021;10:7-37. DOI

13. Tian YM, Guo XN, Braunschweig H, Radius U, Marder TB. Photoinduced borylation for the synthesis of organoboron compounds. Chem Rev 2021;121:3561-97. DOI PubMed

14. Tomasz K, Marcin K. Organoboron compounds in visible light-driven photoredox catalysis. Curr Org Chem 2021;25:994-1027. DOI

15. Mayer RJ, Hampel N, Ofial AR. Lewis acidic boranes, lewis bases, and equilibrium constants: a reliable scaffold for a quantitative Lewis acidity/basicity scale. Chemistry 2021;27:4070-80. DOI PubMed PMC

16. Berger SM, Ferger M, Marder TB. Synthetic approaches to triarylboranes from 1885 to 2020. Chemistry 2021;27:7043-58. DOI PubMed PMC

17. Su X, Bartholome TA, Tidwell JR, et al. 9-borafluorenes: synthesis, properties, and reactivity. Chem Rev 2021;121:4147-92. DOI PubMed

18. He J, Rauch F, Finze M, Marder TB. (Hetero)arene-fused boroles: a broad spectrum of applications. Chem Sci 2020;12:128-47. DOI PubMed PMC

19. Stoian C, Olaru M, Cucuiet TA, et al. Bulky polyfluorinated terphenyldiphenylboranes: water tolerant Lewis acids. Chemistry 2021;27:4327-31. DOI PubMed PMC

20. Hasenbeck M, Gellrich U. Boron-ligand cooperation: the concept and applications. Chemistry 2021;27:5615-26. DOI PubMed PMC

21. Zhang C, Wang J, Su W, Lin Z, Ye Q. Synthesis, characterization, and density functional theory studies of three-dimensional inorganic analogues of 9,10-diboraanthracene-a new class of Lewis superacids. J Am Chem Soc 2021;143:8552-8. DOI PubMed

22. Chardon A, Osi A, Mahaut D, Ben Saida A, Berionni G. Non-planar boron Lewis acids taking the next step: development of tunable Lewis acids, Lewis superacids and bifunctional catalysts. Synlett 2020;17:1639-48. DOI

23. Ben Saida A, Chardon A, Osi A, et al. Pushing the Lewis acidity boundaries of boron compounds with non-planar triarylboranes derived from triptycenes. Angew Chem Int Ed Engl 2019;58:16889-93. DOI PubMed

24. Chardon A, Osi A, Mahaut D, et al. Controlled generation of 9-boratriptycene by Lewis adduct dissociation: accessing a non-planar triarylborane. Angew Chem Int Ed Engl 2020;59:12402-6. DOI PubMed

25. Houghton AY, Hurmalainen J, Mansikkamäki A, Piers WE, Tuononen HM. Direct observation of a borane-silane complex involved in frustrated Lewis-pair-mediated hydrosilylations. Nat Chem 2014;6:983-8. DOI PubMed 
26. Full J, Panchal SP, Götz J, Krause AM, Nowak-Król A. Modular synthesis of organoboron helically chiral compounds: cutouts from extended helices. Angew Chem Int Ed Engl 2021;60:4350-7. DOI PubMed PMC

27. Ando N, Yamada T, Narita H, Oehlmann NN, Wagner M, Yamaguchi S. Boron-doped polycyclic $\pi$-electron systems with an antiaromatic borole substructure that forms photoresponsive B-P Lewis adducts. J Am Chem Soc 2021;143:9944-51. DOI PubMed

28. Budy H, Kaese T, Bolte M, Lerner HW, Wagner M. A chemiluminescent tetraaryl diborane(4) tetraanion. Angew Chem Int Ed Engl 2021;60:19397-405. DOI PubMed

29. Gotoh H, Nakatsuka S, Tanaka H, et al. Syntheses and physical properties of cationic BN-embedded polycyclic aromatic hydrocarbons. Angew Chem Int Ed Engl 2021;60:12835-40. DOI PubMed

30. Chen M, Unikela KS, Ramalakshmi R, et al. A BN-doped cycloparaphenylene debuts. Angew Chem Int Ed Engl 2021;60:1556-60. DOI PubMed

31. Chen X, Meng G, Liao G, et al. Highly emissive 9-borafluorene derivatives: synthesis, photophysical properties and device fabrication. Chemistry 2021;27:6274-82. DOI PubMed PMC

32. Soman R, Chandra B, Bhat IA, et al. $\mathrm{A}_{2} \mathrm{~B}$ - and $\mathrm{A}_{3}$-type boron(III)subchlorins derived from meso-diethoxycarbonyltripyrrane: synthesis and photophysical exploration. J Org Chem 2021;86:10280-7. DOI PubMed

33. Adachi Y, Nomura T, Tazuhara S, Naito H, Ohshita J. Thiophene-based twisted bistricyclic aromatic ene with tricoordinate boron: a new n-type semiconductor. Chem Commun (Camb) 2021;57:1316-9. DOI PubMed

34. Manankandayalage C, Unruh DK, Krempner C. Small molecule activation with intramolecular "inverse" frustrated Lewis pairs. Chemistry 2021;27:6263-73. DOI PubMed

35. Zheng X, Zulkifly I, Heilmann A, McManus C, Aldridge S. Colorimetric metal-free detection of carbon monoxide: reversible CO uptake by a BNB frustrated Lewis pair. Angew Chem Int Ed Engl 2021;60:16416-9. DOI PubMed PMC

36. Zhang YY, Yang GW, Xie R, Yang L, Li B, Wu GP. Scalable, durable, and recyclable metal-free catalysts for highly efficient conversion of $\mathrm{CO}_{2}$ to cyclic carbonates. Angew Chem Int Ed Engl 2020;59:23291-8. DOI PubMed

37. Yang GW, Xu CK, Xie R, Zhang YY, Zhu XF, Wu GP. Pinwheel-shaped tetranuclear organoboron catalysts for perfectly alternating copolymerization of $\mathrm{CO}_{2}$ and epichlorohydrin. J Am Chem Soc 2021;143:3455-65. DOI PubMed

38. Fontaine FG, Courtemanche MA, Légaré MA, Rochette E. Design principles in frustrated Lewis pair catalysis for the functionalization of carbon dioxide and heterocycles. Coord Chem Rev 2017;334:124-35. DOI

39. Zhao T, Hu X, Wu Y, Zhang Z. Hydrogenation of $\mathrm{CO}_{2}$ to formate with $\mathrm{H}_{2}$ : transition metal free catalyst based on a Lewis pair. Angew Chem Int Ed Engl 2019;58:722-6. DOI PubMed

40. Sitte NA, Bursch M, Grimme S, Paradies J. Frustrated Lewis pair catalyzed hydrogenation of amides: halides as active Lewis base in the metal-free hydrogen activation. J Am Chem Soc 2019;141:159-62. DOI PubMed

41. Köring L, Sitte NA, Bursch M, Grimme S, Paradies J. Hydrogenation of secondary amides using phosphane oxide and frustrated Lewis pair catalysis. Chemistry 2021. DOI PubMed

42. Sun Q, Daniliuc CG, Mück-Lichtenfeld C, Bergander K, Kehr G, Erker G. Reductive cleavage of the CO molecule by a reactive vicinal frustrated PH/BH Lewis pair. J Am Chem Soc 2020;142:17260-4. DOI PubMed

43. Rej S, Chatani N. Transient imine as a directing group for the metal-free o-C-H borylation of benzaldehydes. $J$ Am Chem Soc 2021;143:2920-9. DOI PubMed

44. Légaré MA, Courtemanche MA, Rochette É, Fontaine FG. BORON CATALYSIS. Metal-free catalytic C-H bond activation and borylation of heteroarenes. Science 2015;349:513-6. DOI PubMed

45. Iqbal SA, Pahl J, Yuan K, Ingleson MJ. Intramolecular (directed) electrophilic C-H borylation. Chem Soc Rev 2020. DOI PubMed

46. Lam J, Szkop KM, Mosaferi E, Stephan DW. FLP catalysis: main group hydrogenations of organic unsaturated substrates. Chem Soc Rev 2019;48:3592-612. DOI PubMed

47. Fontaine FG, Desrosiers V. Boron Lewis pair mediated C-H activation and borylation. Synthesis 2021. DOI

48. Ma Y, Lou SJ, Hou Z. Electron-deficient boron-based catalysts for C-H bond functionalisation. Chem Soc Rev 2021;50:1945-67. DOI PubMed

49. Légaré MA, Pranckevicius C, Braunschweig H. Metallomimetic chemistry of boron. Chem Rev 2019;119:8231-61. DOI PubMed

50. Prey SE, Wagner M. Threat to the throne: can two cooperating boron atoms rival transition metals in chemical bond activation and catalysis? Adv Synth Cat 2021;363:2290-309. DOI

51. Liu Y, Dong W, Li ZH, Wang H. Methane activation by a borenium complex. Chem 2021;7:1843-51. DOI

52. Osi A, Mahaut D, Tumanov N, et al. Taming the Lewis Superacidity of non-planar boranes: C-H bond activation and non-classical binding modes at Boron. Angew Chem Int Ed 2021. DOI

53. Basak S, Biswas JP, Maiti D, Transition-metal-catalyzed C-H arylation using organoboron reagents. Synthesis 2021;53:3151-79. DOI

54. Hoque ME, Hassan MMM, Chattopadhyay B. Remarkably efficient iridium catalysts for directed $\mathrm{C}\left(\mathrm{sp}^{2}\right)-\mathrm{H}$ and $\mathrm{C}\left(\mathrm{sp}^{3}\right)$-H borylation of diverse classes of substrates. J Am Chem Soc 2021;143:5022-37. DOI PubMed 